\title{
The Discovery of Weak Neutral Currents
}

\author{
Dieter Haidt \\ DESY, Hamburg
}

Historic Neutrino Conference

Paris, 5-7 September 2018 


\section{GARGAMELLE}

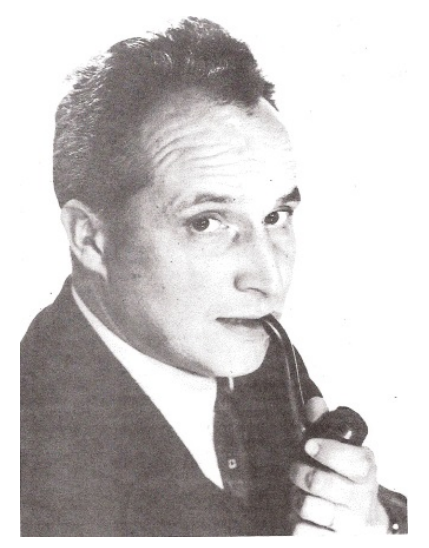

André Lagarrigue

- the father of

Gargamelle

\section{Brief chronology}

1963 conceived as large

$2^{\text {nd }}$ generation bubble chamber

geometry $R=1 \mathrm{~m} \quad \mathrm{~L}=4.8 \mathrm{~m}$

heavy liquid $\left(\mathrm{CF}_{3} \mathrm{Br}\right.$ and $\left.\mathrm{C}_{3} \mathrm{H}_{8}\right)$

good identification of final state

1970 installed at CERN

1971 first run in WB $v$ and $\bar{v}$-beams

1973 discovery of NC

1978 break down (crack)

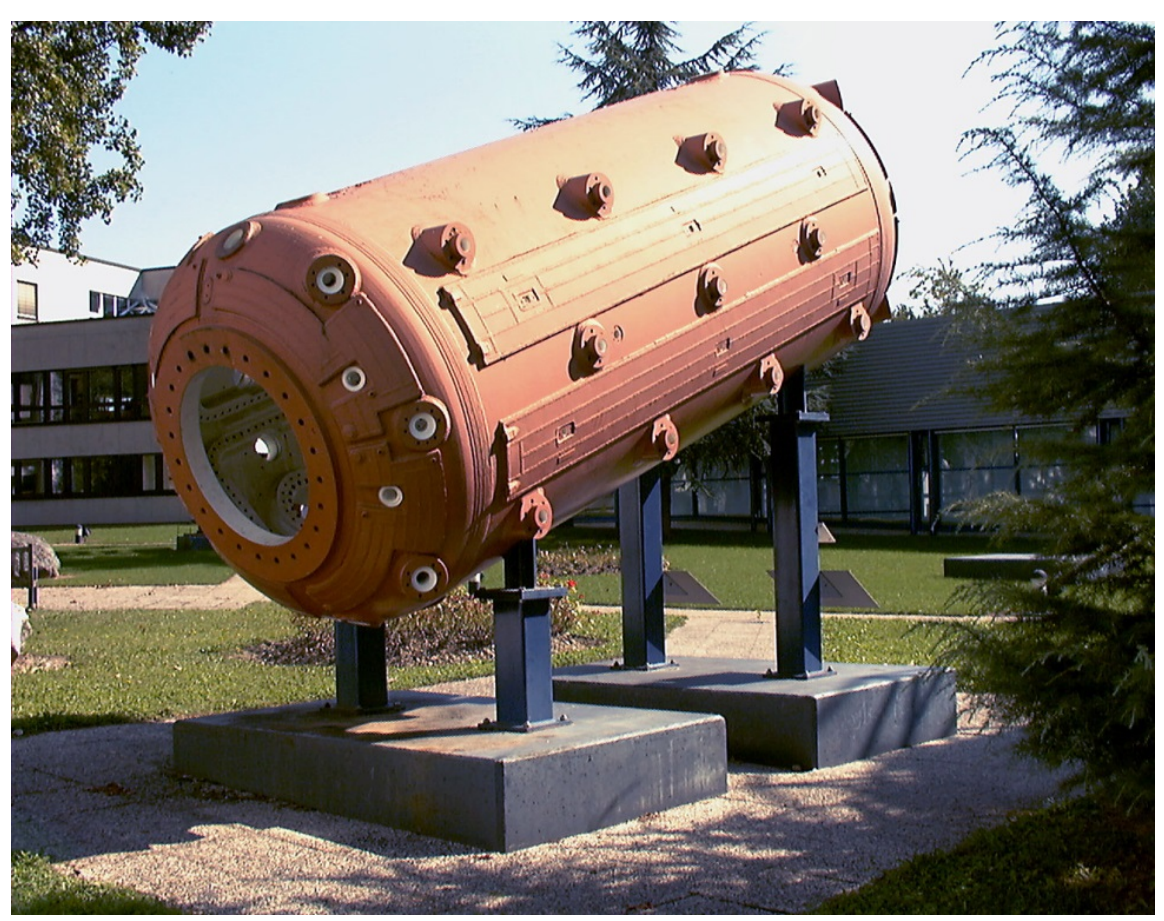

Gargamelle emerita

Today exhibited on CERN ground 


\section{A Historic Moment}

End of 1971 : M.K.Gaillard, B.Zumino, J.Prentki, C.Bouchiat,

M.Veltman approach Gargamelle and Weinberg HPW

1. Weinberg: There is a model combining leptonic weak and electromagnetic interactions based on the gauge symmetry $\mathrm{SU}(2) \times \mathrm{U}(1)$

2. 't Hooft : this model is renormalizable

3. The key element : weak neutral currents

Request : look for $v+e \rightarrow v+e$ and $v+N \rightarrow v+X$ ! 


\section{Two Detectors}

\section{Gargamelle at CERN PS}

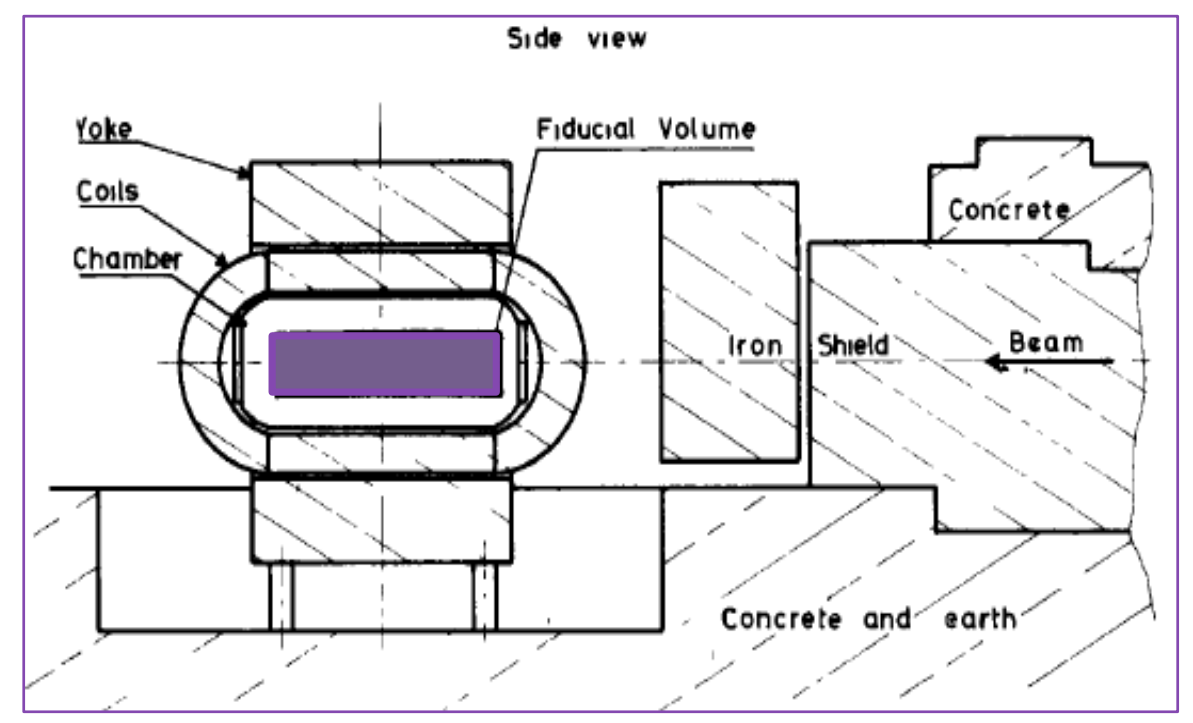

Heavy Liquid Bubble Chamber Magnet Coil and iron yoke Thick iron Shielding
E-1A at NAL PS

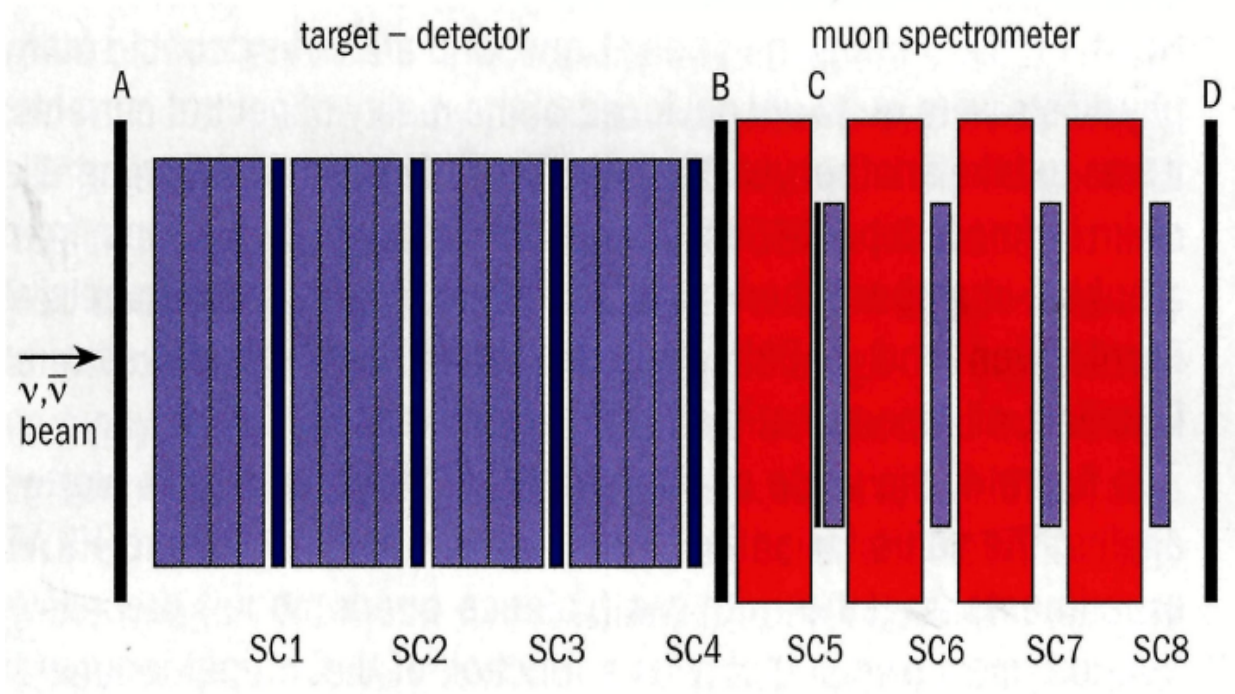

Liquid Scintillation Calorimeter Magnetic Iron Spectrometer 


\section{GARGAMELLE}

\section{E-1A HPW}

\section{- Approved 1970}

priority : nucleon structure

- Data taking 1971/2

- Heavy liquid bubble chamber strong magnet coils, shielding

- CERN PS Booster $24 \mathrm{GeV}$

- WB hornfocussed $v$ and $\bar{v}$ beams $1-10 \mathrm{GeV}$

- Record everything

Note: Excellent research topics - but not Neutral Currents !

Sudden change of priority to NC search in 1972
: Approved 1970 priority : W search

- Data taking end $1972+$ spring 73

- Target calorimeter + muon spectrometer

- NAL PS 200/300 GeV

- WB beam mixed $v$ and $\bar{v}$ 10-200 GeV

- Set trigger to select interesting events 


\section{Searching for a new effect}

1. Define signature of candidates for the new effect

2. Investigate all processes simulating this signature all means in practice all known

\section{Claim a discovery if \\ \# signal 》 \# background}




\section{Gargamelle}

Signal

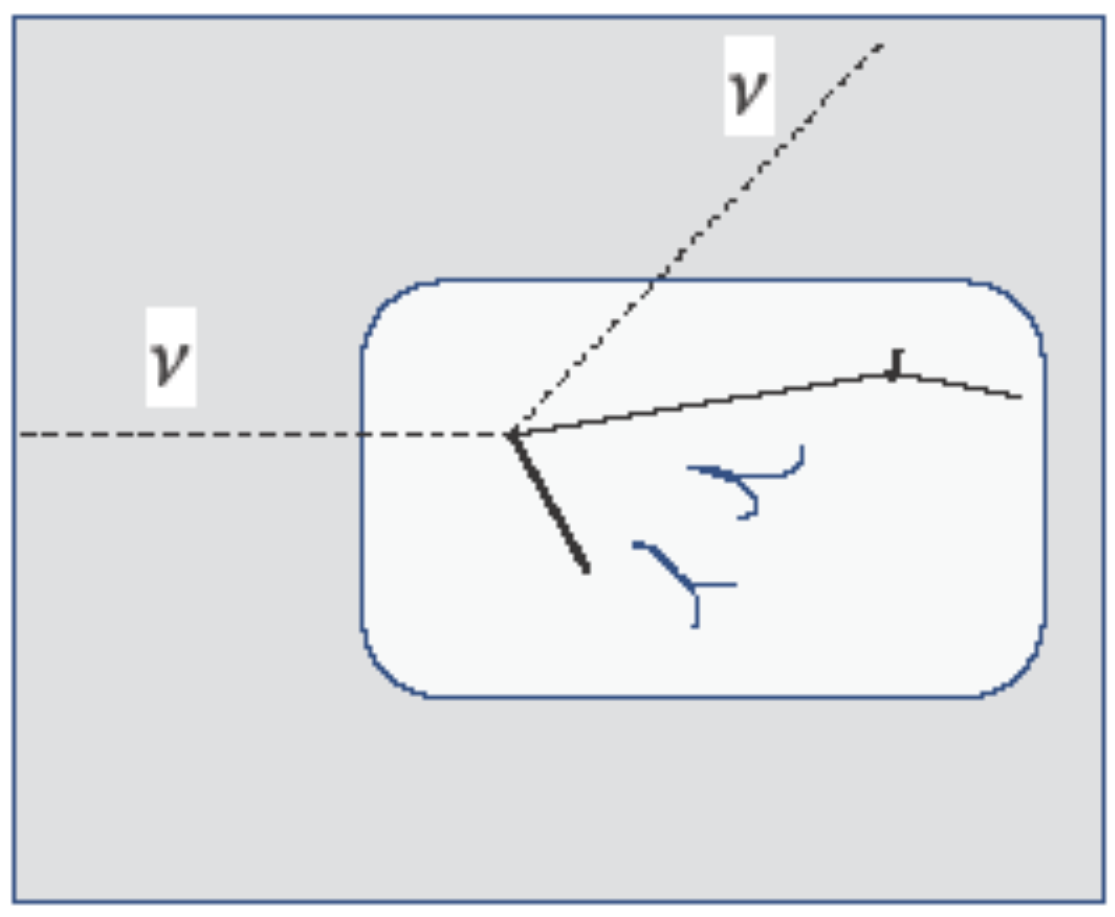

Background

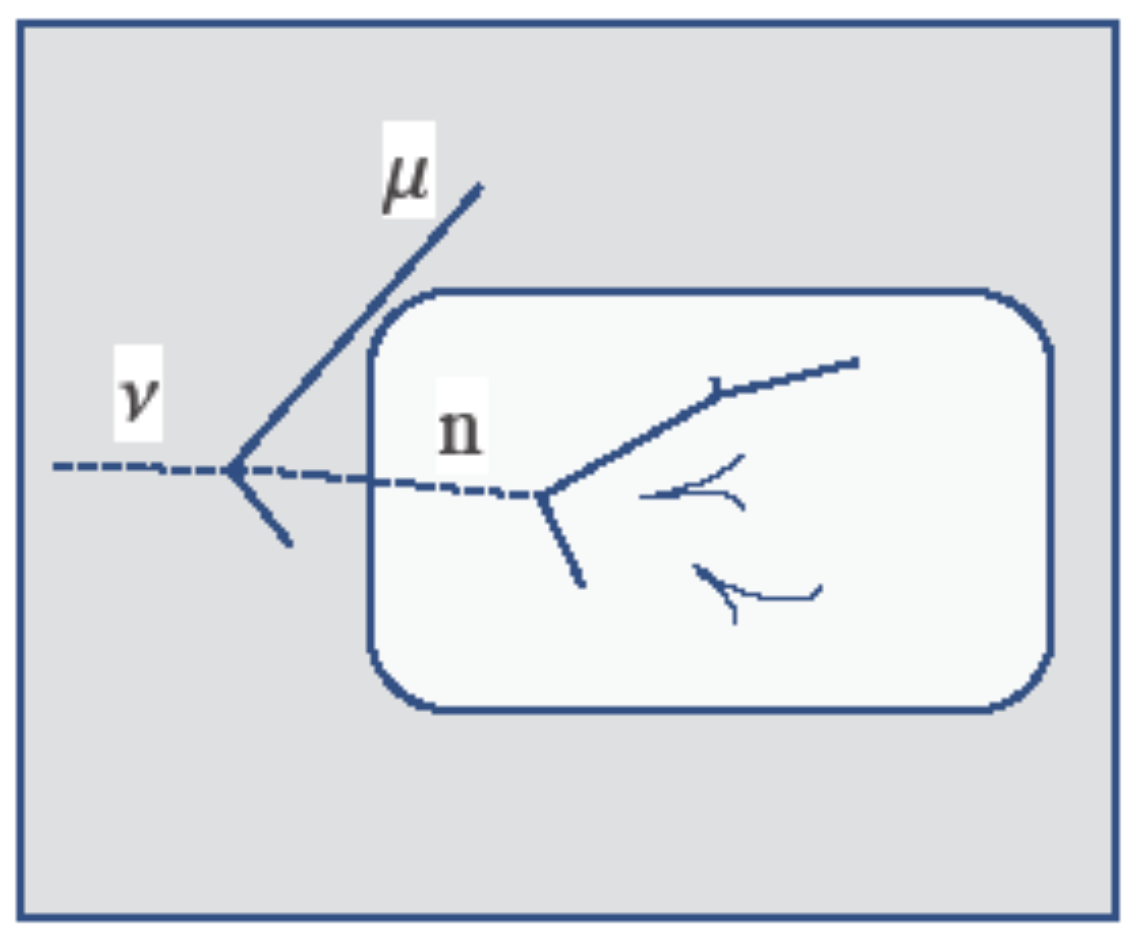




\section{E-1A}

\section{Signal}

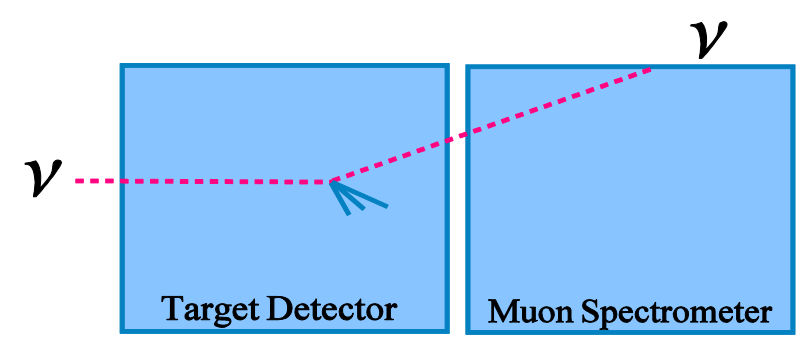

\section{Background}

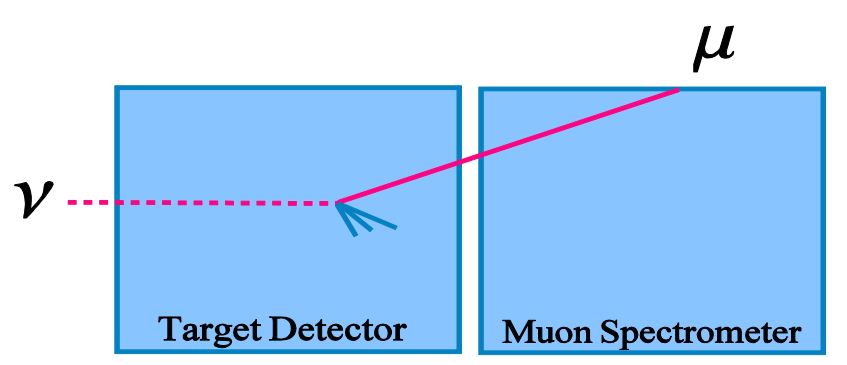

Need two independent triggers : energy deposition and no muon
$\mathrm{CC}$ events with wide angle muon escaping No worry about punch through 


\section{A Happy Circumstance}

- Scanning rules were setup before experiment started

Class $\mathbf{A}$ : events with muon candidate

Class B : events with identified hadrons

Class C : one or more protons

Class $\mathbf{D}$ : only electrons and positrons

$\mathbf{v}$-induced events are in class $A$.

$\mathbf{n}$-induced events are in class $A$, if a charged final state hadron fakes a muon

$\mathbf{n}$-induced events are in class $B$, if final state particles are identified as hadrons

- Class B serves to estimate the unavoidable neutron background in class $A$

The challenge : Are there $\mathbf{v}$-induced events without muon in the final state?

If so, they are already in class B : start NC search without delay 


\section{An exciting leptonic NC candidate}

360000 pictures scanned Isolated forward $e$ found at Aachen in Dec 1972. Interpretation:

$$
\overline{v_{\mu}} \mathrm{e} \rightarrow \overline{v_{\mu}} \mathrm{e}
$$

Properties of electron:

$>$ Identification: unique by bremsstrahlung and curling

$>$ Energy $385 \pm 100 \mathrm{MeV}$

$>$ Angle $1.4 \pm 1.4$ degree

Background : $0.03 \pm 0.02$

$$
\begin{gathered}
v_{e} n \rightarrow e+p \\
\text { (proton invisible) }
\end{gathered}
$$

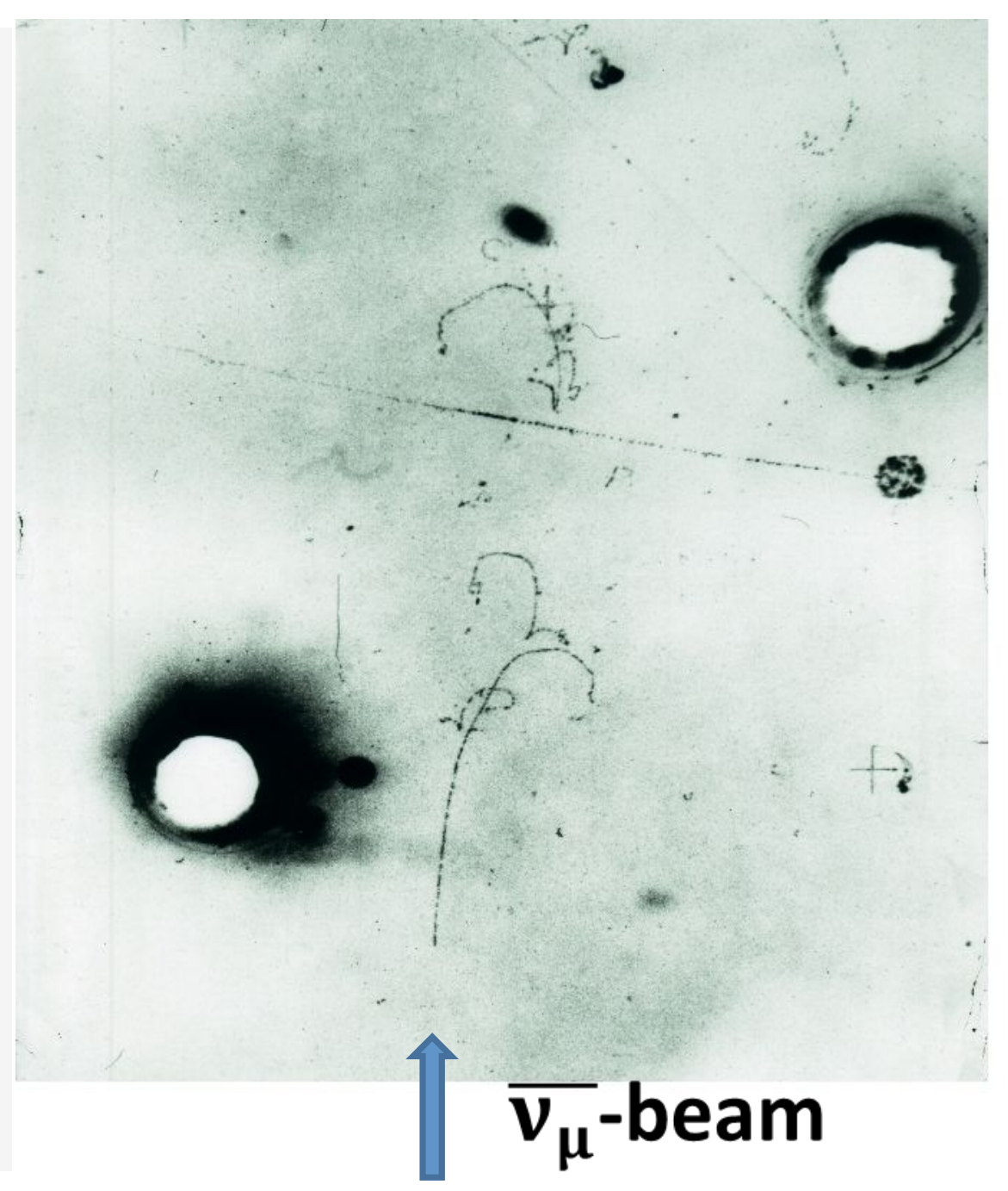




\section{An early NC candidate}

- 3-prong event

- very clean

- no muon

- total visible energy about $6 \mathrm{GeV}$

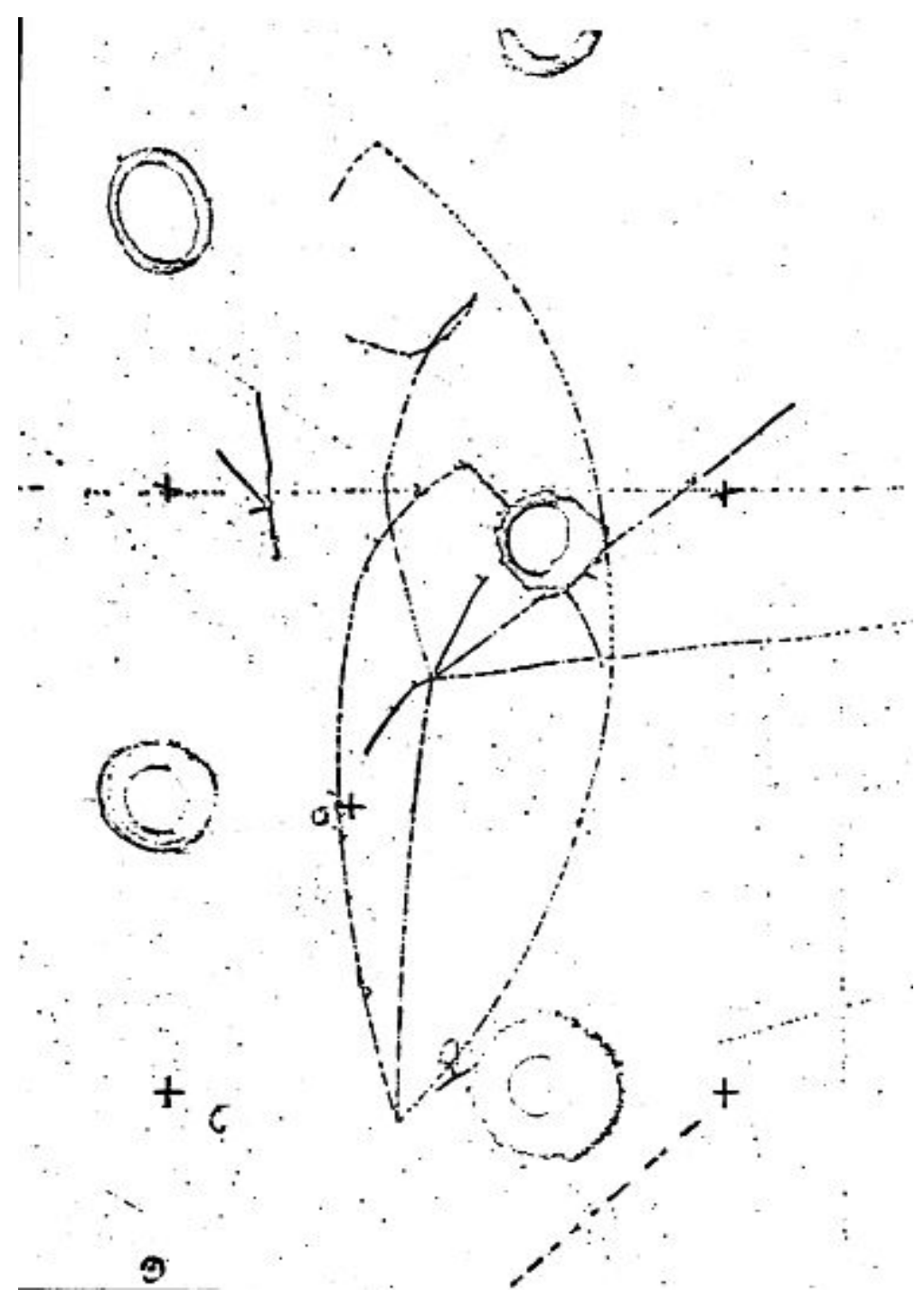




\section{The March 1973 Meeting Euphory and Doubts}

\section{Ezuphory}

- The unique $\bar{v} e$-candidate

- Many candidates without $\mu$

- Subsample of CC events ignoring the $\mu$ and imposing the same criteria on hadrons

Expected shape of distribution along chamber axis:

1. If NC candidates $n$-induced, then exponential falloff

2. If NC candidates v-induced, then flat distribution

3. The CC-subsample flat

\section{Distinctive features:}

$\mathrm{n}$ : exponential falloff $(\lambda \ll<)$

$v$ : everywhere flat $(\lambda \gg L)$

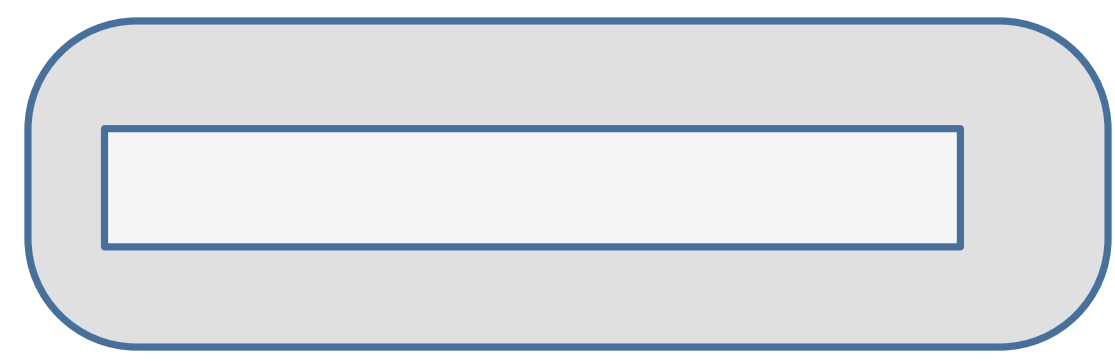

Distribution along chamber

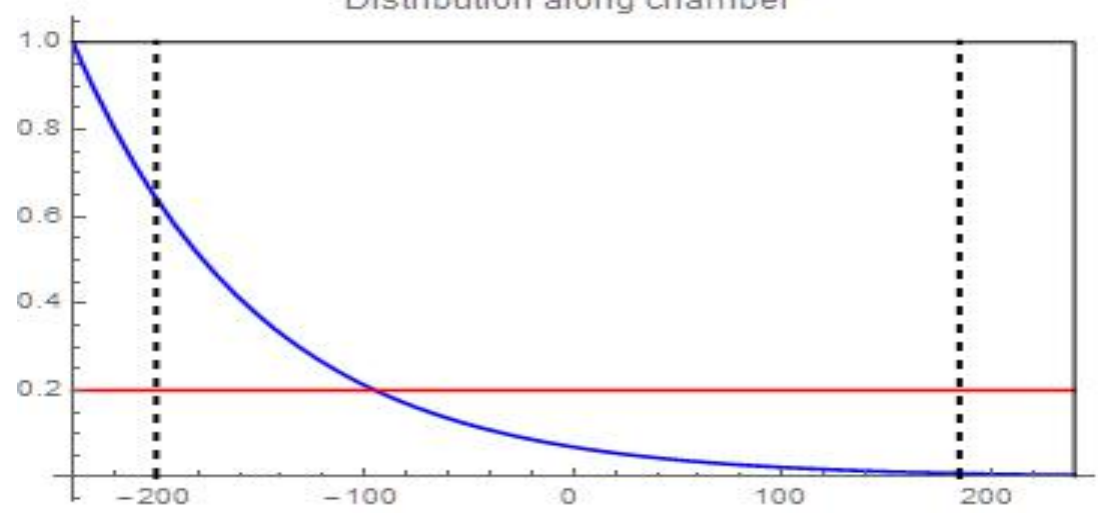




\section{The Data}
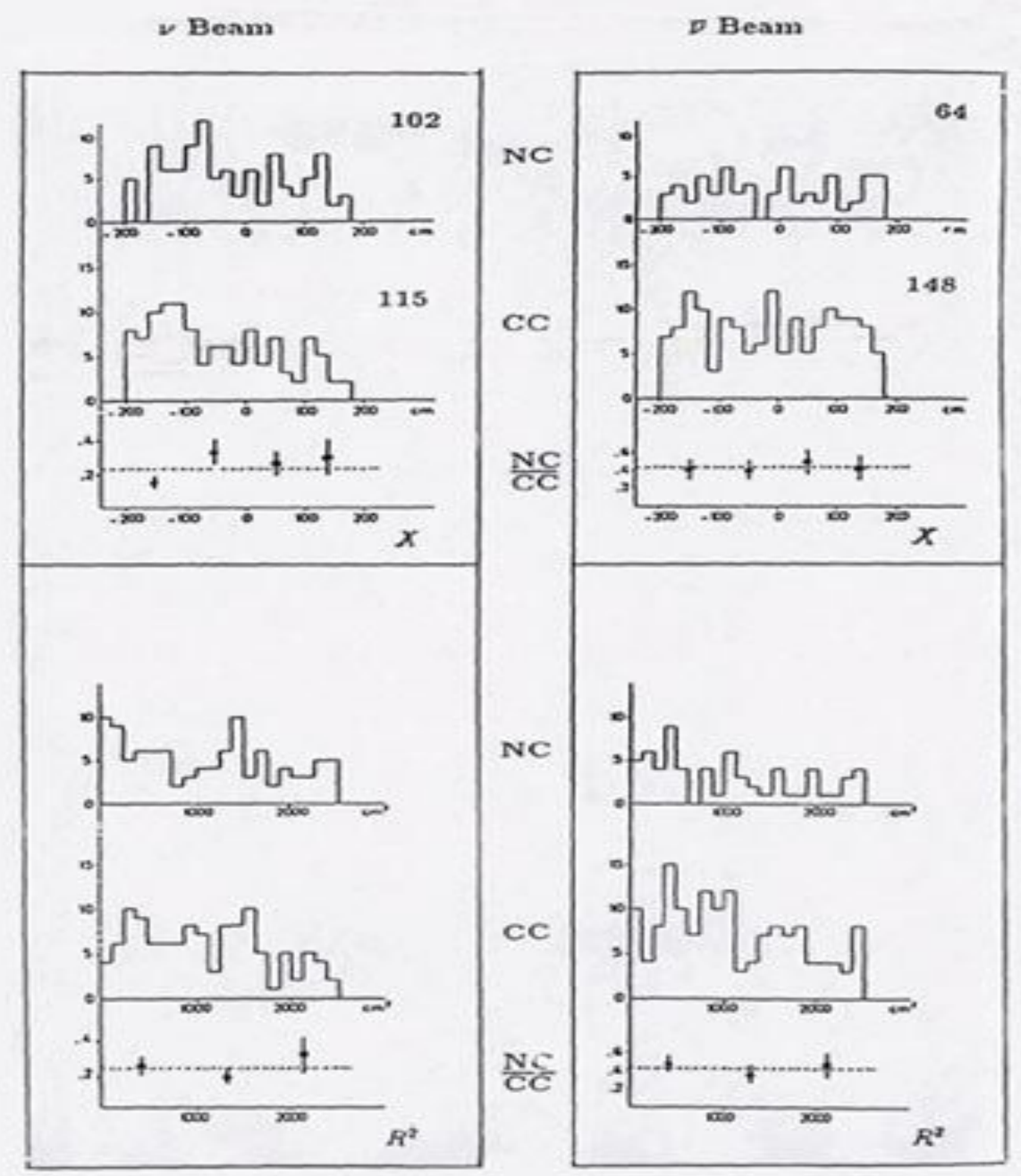

- Compare hadron final state of NC with $\mathrm{CC}(\mathrm{no} \mu)$ and form NC/CC

$\mathrm{X}=$ along beam direction

$\mathrm{R}=$ radial

- $\quad \mathrm{NC}=\mathrm{v}$ - or $\mathrm{n}$-induced ?

- 3 arguments favour v-origin

$\mathrm{NC} / \mathrm{CC}$ is flat and big

$\mathrm{NC}$ look v-like

NC do not look n-like

- Oversimplified ORSAY Monte Carlo disfavours neutrons

A discovery at hand ? 


\section{Damped Euphory}

Two critical arguments

- Neutrons make cascades

$\rightarrow \mathrm{n}$-background $\sim$ cascade length ORSAY MC underestimates neutrons

- Broad neutrino beam generates neutrons from sides $\rightarrow$ appearing as flat distribution (sensitive to energy and angular distribution of neutrons

The setup in terms of interaction lengths

- The chamber is embedded in heavy material

- \#v events $\sim \lambda$

- Huge number of $v$-interactions outside the chamber

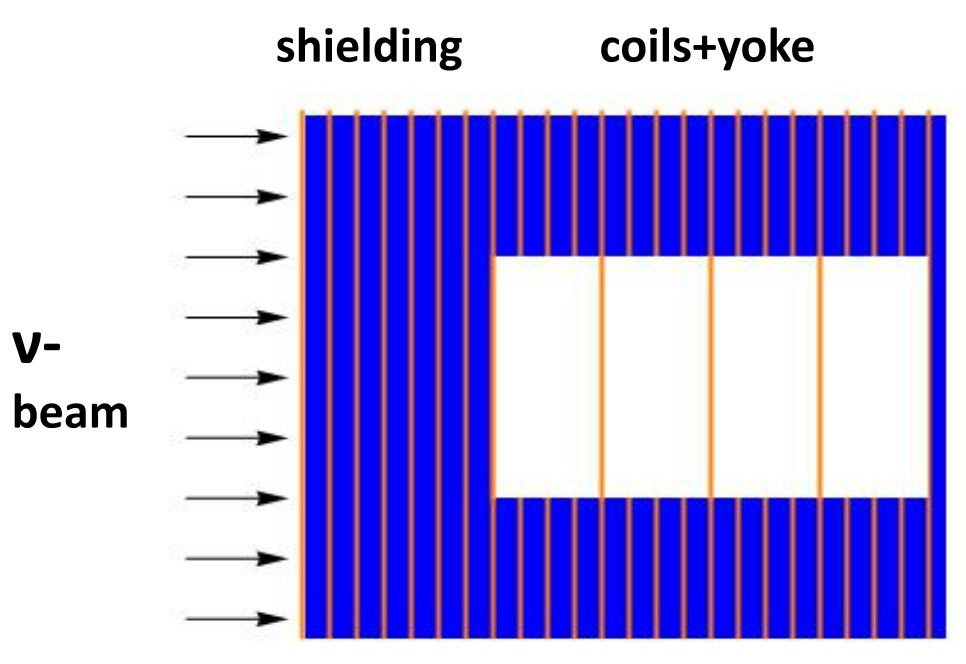




\section{Neutron Background Calculation}

\section{Ingredients}

Matter distribution

Neutrino flux

Dynamics of final hadron state

Evolution of hadrons in matter
Complicated, but known

Measured

From v-events

Need cascade model

Cascade Model : start March - ready beginning of July 1973

At first hopeless : short time and complexity Breakthrough : cascade only transported by nucleon ( $>1 \mathrm{GeV}$ ) Linear problem : need only the energy loss per collision Elasticity distribution has been extracted from $\mathrm{pp}$-data

Conclusion: Absolute prediction of neutron background no free parameter 


\section{Appearance of neutron interactions}

\section{B-event:}

v-interaction upstream in shielding

Observe in chamber the end of the neutron-cascade

AS-event:

v-interaction inside chamber Observe in chamber the beginning of the neutron- cascade
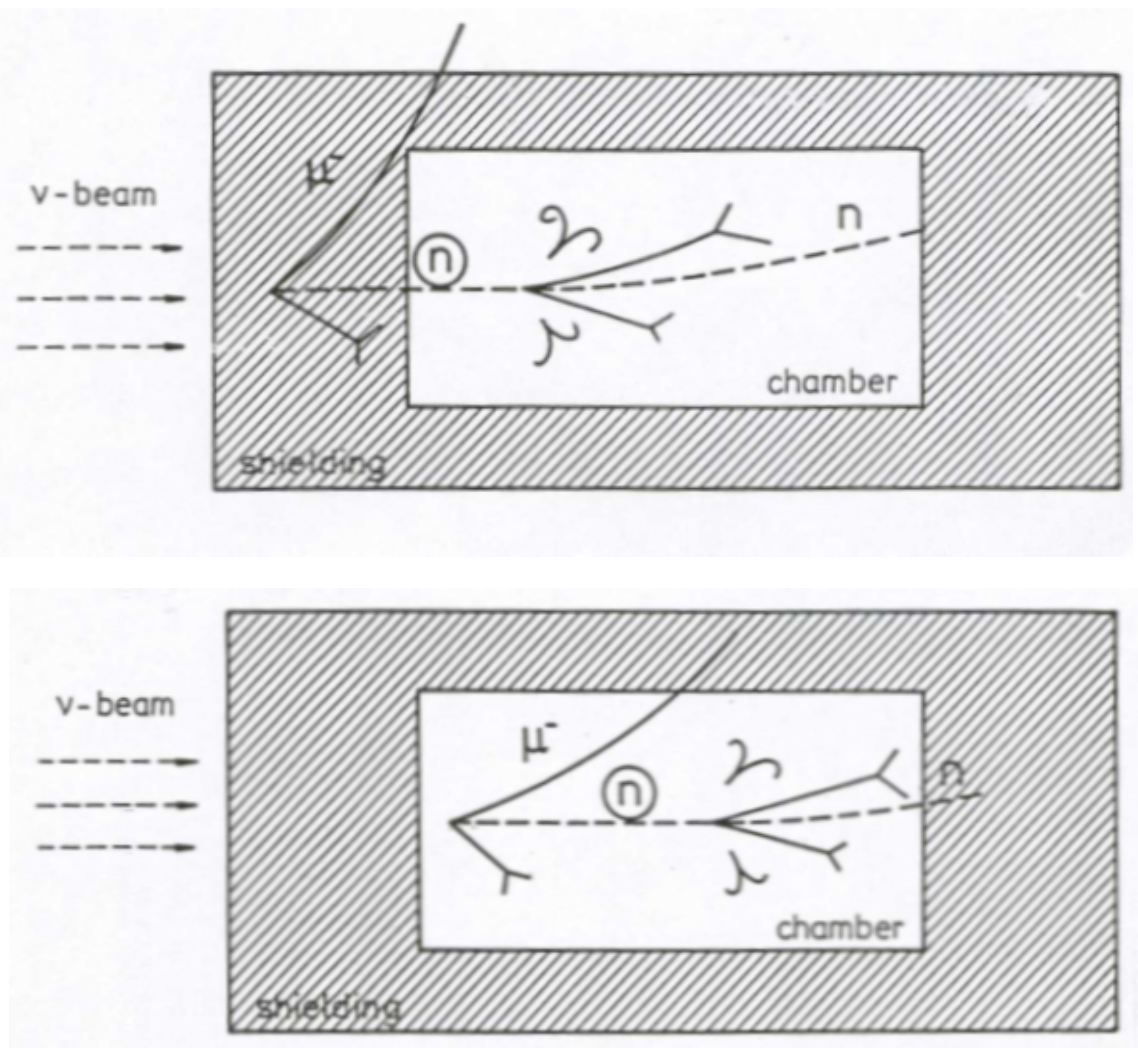

Predict B/AS: optimal use of data model dependence reduced (except for cascade effect) 


\section{The Proof}

Beginning of July 1973 : 102 NC candidates in v-film and 15 AS

Worst case hypothesis : All NC are background

Cascade program predicts :

$$
\begin{aligned}
\frac{\# B}{\# A S}=\frac{\# N C}{\# A S}=\frac{102}{15} \\
\frac{B}{A S}=1 \pm 0.3
\end{aligned}
$$

Similarly for antineutrino data

Hypothesis must be rejected: a new effect exists

After hot and intense discussions submit paper July 25, 1973 to Phys.Lett. 


\section{Internal Method}

Idea: Reconstruct for each event the flight direction from vector sum of final state hadrons Then apply classical Bartlett method to obtain the apparent interaction length

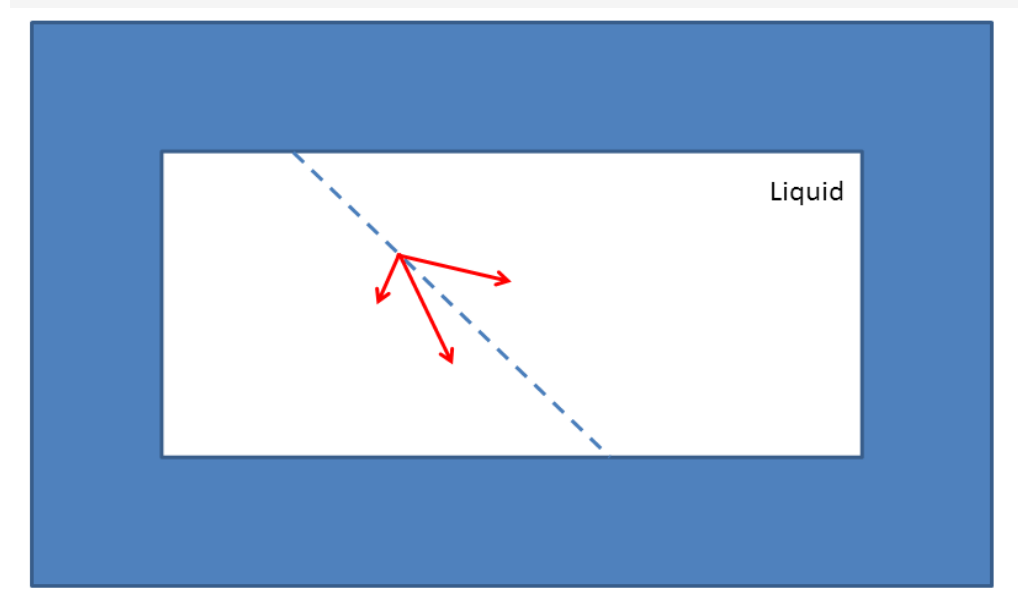

Probability distribution :

$$
\varphi(x) d x=\frac{e^{-x / \lambda}}{1-e^{-L / \lambda}} \frac{d x}{\lambda}
$$

Measure : flight and potential paths $\mathrm{x}$ and $\mathrm{L}$ for each event

Max Likelihood-fit to NC and CC samples

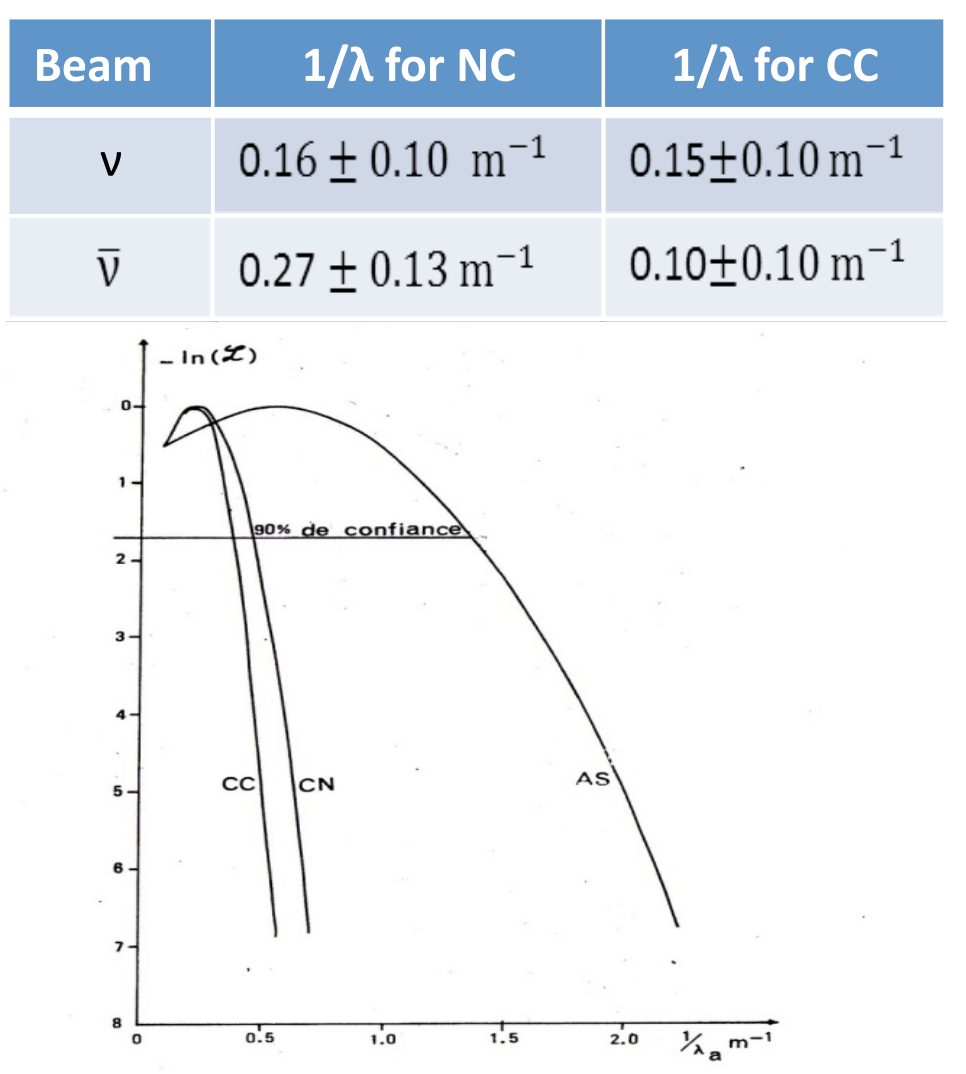

Conclusion : $1 / \lambda(N C) \ll 1 / \lambda(n)$ 


\section{The Authors of the Discovery Papers}

SEARCH FOR ELASTIC MUON-NEUTRINO ELECTRON SCATTERING

$$
\begin{aligned}
& \text { FJ. HASERT, H. FAISSNER, W. KRENZ, J. Von KROGH, } \\
& \text { D. LANSKE, J. MORFIN, K. SCHULTZE and H. WEERTS } \\
& \text { III Physikalisches Institut der technischen Hochschule, Aachen, Germany }
\end{aligned}
$$

G.H. BERTRAND-COREMANS, J. LEMONNE, J. SACTON, W. Van DONINCK and P. VILAIN* I Interuniversity Institute for High Energies, U.L.B., V.U.B. Brussels, Belgium

C. BALTAY ${ }^{*}$, D.C. CUNDY, D. HAIDT, M. JAFFRE, P. MUSSET, A. PULLIA ${ }^{*_{3}}$ S. NATALI ${ }^{* 4}$, J.B.M. PATTISON, D.H. PERKINS ${ }^{* 5}$, A. ROUSSET, W. VENUS ${ }^{* 6}$ and H.W. WACHSMUTH

V. BRISSON, B. DEGRANGE, M. HAGUENAUER, L. KLUBERG, U. NGUYEN-KHAC and P. PETIAU Laboratoire de Physique des Hautes Energies, Ecole Polytechnique, Paris, France

E. BELLOTTI, S. BONETTI, D. CAVALLI, C. CONTA ${ }^{*} 7$, E. FIORINI and M. ROLLLER Istituto di Fisica dell 'Universito, Milano and I.N.F.N. Milano, Italy

B. AUBERT, L.M. CHOUNET, P. HEUSSE, A. LAGARRIGUE, A.M. LUTZ and J.P. VIALLE Laboratoire de l'Accélérateur Linéaire, Orsay, France

F.W. BULLOCK, M.J. ESTEN, T. JONES, J. MCKENZIE, A.G. MICHETTE ${ }^{*} 8$ G. MYATT ${ }^{* s}$, J. PINFOLD and W.G. SCOTT*s, University College, University of London, England

Received 2 July 1973
OBSERVATION OF NEUTRINO-LIKE INTERACTIONS WITHOUT MUON OR ELECTRON IN THE GARGAMELLE NEUTRINO EXPERIMENT

$$
\begin{aligned}
& \text { F.J. HASERT, S. KABE, W. KRENZ, J. Von KROGH, D. LANSKE, J. MORFIN, } \\
& \text { K. SCHULTZE and H. WEERTS }
\end{aligned}
$$

III. Physikalisches Institut der Technischen Hochschule, Aachen, Germany

G.H. BERTRAND-COREMANS, J. SACTON, W. Van DONINCK and P. VILAIN* Interuniversity Institute for High Enerǵies, U.L.B., V.U.B. Brussels, Belgium

U. CAMERINI*2 , D.C. CUNDY, R. BALDI, I. DANILCHENKO ${ }^{* 3}$, W.F. FRY*2, D. HAIDT, S. NATALI ${ }^{* 4}$, P. MUSSET, B. OSCULATI, R. PALMER *4, J.B.M. PATTISON, D.H. PERKINS ${ }^{* 6}$, A. PULLIA, A. ROUSSET, W. VENUS*7 and H. WACHSMUTH CERN, Geneva, Switzerland

V. BRISSON, B. DEGRANGE, M. HAGUENAUER, L. KLUBERG, U. NGUYEN-KHAC and P. PETIAU

Laboratoire de Physique Nucléaire des Hautes Energies, Ecole Polytechnique, Paris, France

E. BELOTTI, S. BONETTI, D. CAVALLI, C. CONTA ${ }^{* 8}$. E. FIORINI and M. ROLLIER Istituto di Fisica dell'Università, Milano and I.N.F.N. Milano, Italy

B. AUBERT, D. BLUM, L.M. CHOUNET, P. HEUSSE, A. LAGARRIGUE, A.M. LUTZ, A. ORKIN.LECOURTOIS and J.P. VIALLE Laboratoire de l'Accélérateur Linéaire, Orsay, France

F.W. BULLOCK, M.J. ESTEN, T.W. JONES, J. McKENZIE, A.G. MICHETTE* G. MYATT* and W.G. SCOTT*6,* University College, London, England

Received 25 July 1973

Deceased: Lagarrigue, Rousset, Musset, Rollier, Faissner, Schultze, Lanske, Nguyen-Khac, Camerini, Fry, Wachsmuth, Natali, Bullock, Violette Brisson 


\section{The Electron-Photon Symposium August 27-31,1973 at BONN}

For the first time high energy neutrino physics included $\rightarrow$ from now on Lepton-Photon Conference

GGM presentation of results on weak neutral currents

1. The published Gargamelle analysis

2. Include last minute contribution from HPW

(based on analysis submitted to PRL in May 1973)

3. Contribution from Argonne $12 \mathrm{ft} B C$ : exclusive 1-pion channel

4. First attempt to compare with theory: $\sin ^{2} \theta \approx 0.3$ 


\section{The Hot Fall}

- Prominent physicists disbelieve the Gargamelle analysis : "You have rediscovered the neutron!"

- GGM had anticipated all their arguments and rejected them firmly

- Bad stroke : HPW runs with modified detector: NC effect disappeared

- The CERN Directorate got worried

- Instead of doubting HPW Gargamelle was blamed to be wrong I

- General suspicion: GGM is wrong because of error in treating neutrons

- Way out : YES or NO by special exposure of Gargamelle with proton pulses to test explicitly the neutron cascade

Modified HPW-detector

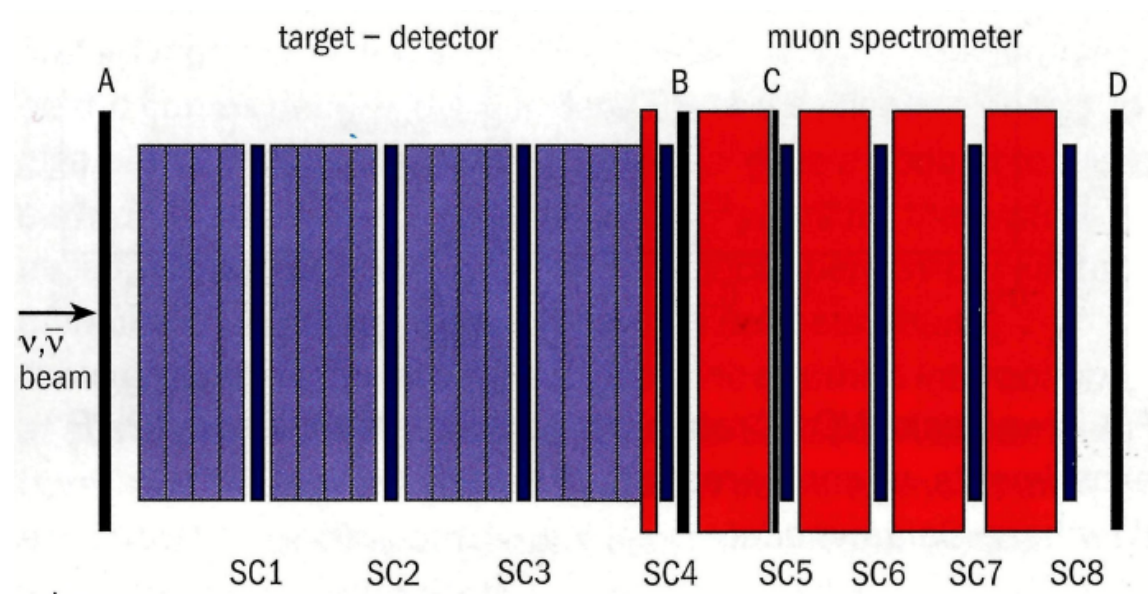

Introduce $13^{\prime}$ iron plate (red) : increase muon acceptance fatal consequence : punchthrough NC misidentified as CC thus : loose NC effect 


\section{HPW Publication History}

- July 17, 1973

Rubbia informs Lagarrigue : 100 NC events

- $\quad$ August 3, 1973 submitted tp PRL also submitted to Bonn Conference

- September 14, 1973 slightly revised

- Collaboration decides to postpone and wait for more data with modified detector

- November 13, 1973

HPW informs Lagarrigue about absence of NC

- Februar 25,1974

new paper submitted to $P R L$

- $\quad$ April 1974

Published in PRL 32 (1974) 800

Existence of neutral currents confirmed

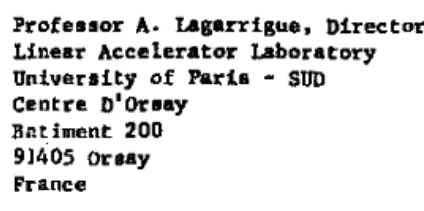

Dear Profeasor Legarrigue:

We orite to inform you of the preliminary result of our recent experiment to search for neutrino interactions without final state muons. As you know, our apparatus was modified to provide a much larger detection
efficiency for muons relat ive to the apparatug that was used in our earlier efficiency for muons relative to the apparatus that was used in our earlier
search for muonless events. We also improved our ability to locate accuchreshold on the totel enargy of the hadrons to the finel otate.

From about one half of the data obtained in our recent run, we find the raw ratio $R_{\text {ray }}=0.18 \pm 0.03$. We estimate the muon detection

efficiency of the apparatus for the enriched ent ineutrino beam that was ased in this experiment to be approximately 0.85. Taking into account small backgrounds produced by incident neutrons and by $\nu_{e}$ in the tncident beam, the corrected ratio is $R_{\text {corr }}=0.02+0.05$, where the error 1nc1udes an estimate of the uncertaincy in the calcelated detection efficiency. We are continulag to process the remainder of the data and to improve our

We have written a paper intended for Phyoical Review letters which will soon be submitted. A copy will, of course, be sent to you but for obvious reasons we wanted to convey our result informally to you before its publication.

with kindest regards

Yours sincerely,

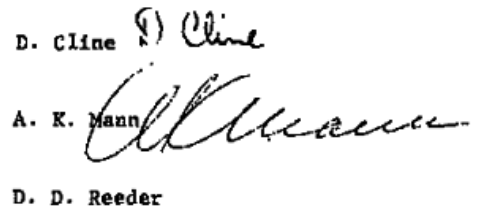




\section{Cascades really exist}

- Event from the special exposure of Gargamelle in Nov/Dec 1973

- A proton of $7 \mathrm{GeV}$ is entering and generating (event 3241671 view2)

a neutron cascade

- The measurement of the first interaction gives the apparent interaction length of the chamber liquid

- Similarly the last interaction with energy deposition exceeding $1 \mathrm{GeV}$ gives the effective cascade length

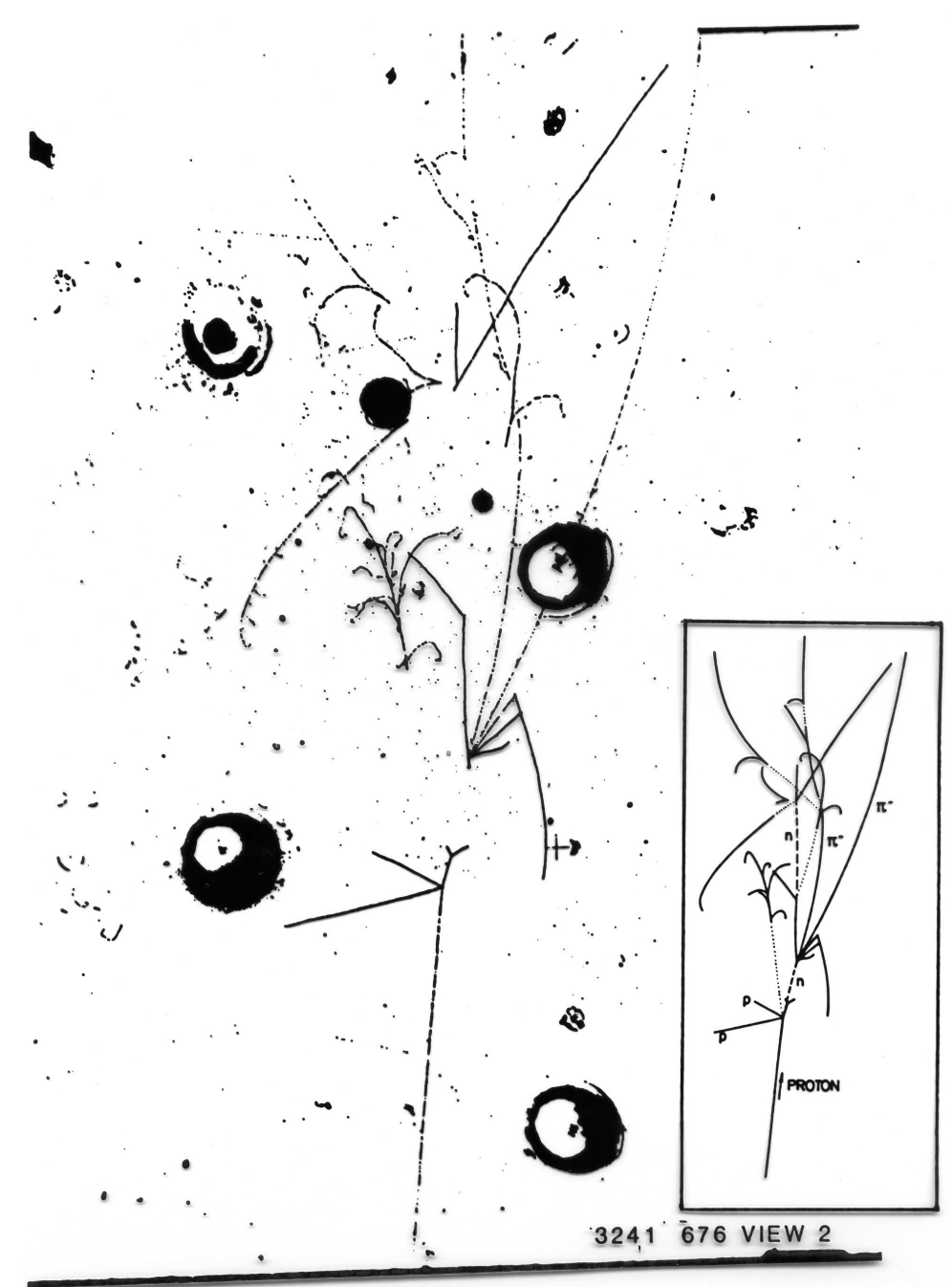




\section{Check the Background Calculation}

- Special runs in Nov+Dec 1973 anticipate what should be observed

- Gargamelle exposed to fast extracted proton pulses of 4, 7, 12 and $19 \mathrm{GeV}$

- Measure apparent interaction length in chamber

- Measure cascade length

- Compare with prediction of

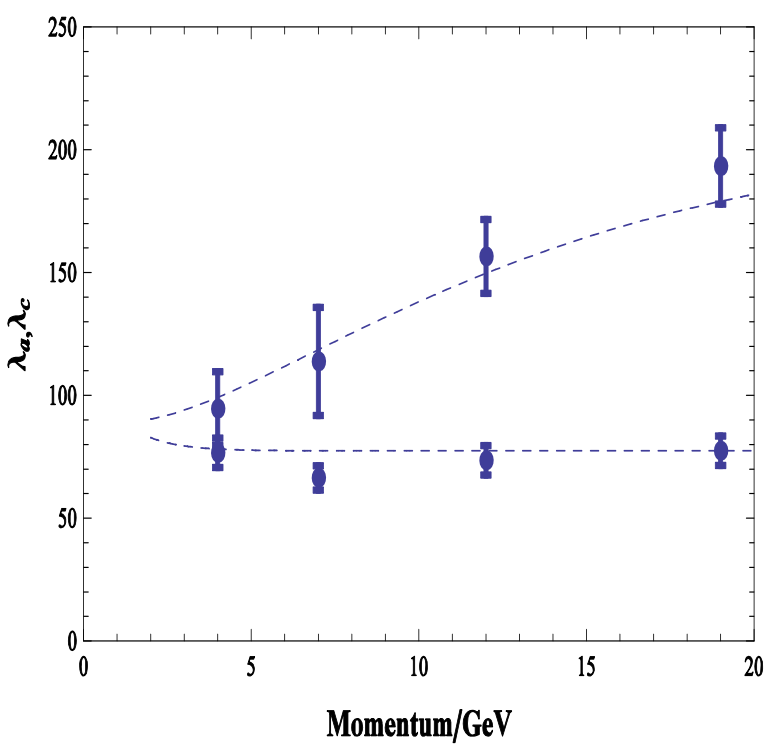
neutron program (dotted lines)

- Reported to APS Meeting Wshington (April 1974)

All aspects of the cascade program are confirmed 


\section{Spring 1974 : The Happy End}

1. Gargamelle

$>$ Double statistics - good consistency

$>$ Neutron background accounts for only $10 \%$ of the candidates proven by absolute calculation and backed up by internal method cascade effect is experimentally confirmed

2. HPW confirms finally muonless events (the alternating currents)

3. ANL : $12^{\prime} B C$ exclusive $n \pi^{+}$and $p \pi^{0}$ production

4. CITF : new experiment at NAL in narrow band $v$ and $\bar{v}$ new method: event length

The existence of weak neutral currents is finally accepted 


\section{The Impact of the Discovery}

: All major laboratories define a long range research program to explore the new force

- Two immediate applications

1. Gravitational collapse

$$
W \rightarrow e v \text { also } Z \rightarrow v v \quad(e, \mu, \tau)
$$

2. Predict $\mathrm{W}$ - and Z-masses

$$
M_{W}=\frac{\sqrt{\frac{\pi \alpha}{\sqrt{2} G}}}{\sin \theta}=\frac{37.3 \mathrm{GeV}}{\sin \theta} \approx 70 \mathrm{GeV}
$$

Propose $\bar{p} p$ experiment CERN collider
: Start the electroweak way: weak and electromagnetic forces are on equal footing

- Breakthrough to gauge theories radiative effects nonabelian nature

- Develop and test models

- Push frontiers in energy $\rightarrow$ new colliders precision $\rightarrow$ large calorimeters

- Large collaborations

- Computing 


\section{Epilog}

- Gargamelle was an excellent collaboration with an excellent pioneering spirit

- It was an exciting time seeing the huge progress of electroweak physics and QCD

- It was my first large collaboration, though small in today's standard

- It was a life without email, without ready-to-use computer codes, without laptop, but punching cards, handwritten slides,...

It was an honour for me to have been a member of Gargamelle and to feel the responsibility in a discovery situation 